\title{
Severe clinical toxicity caused by 25I-NBOMe confirmed analytically using LC-MS-MS method
}

\author{
Wojciech Waldman ${ }^{1,2}{ }^{凶}$, Maria Kała ${ }^{3}$, Wojciech Lechowicz ${ }^{3}$, Dominika Gil ${ }^{3}$ and \\ Jacek Sein Anand ${ }^{1,2}$ \\ 'Department of Clinical Toxicology, Medical University of Gdansk, Gdańsk, Poland; 2Pomeranian Center of Toxicology, Gdańsk, Poland; ${ }^{3}$ nstitute \\ of Forensic Research, Kraków, Poland
}

Rhabdomyolysis is a relatively rare, but potentially serious complication of various diseases. Muscular injury and resultant release of electrolytes, myoglobin and other enzymatic proteins e.g. creatine kinase (CK) into circulation may result in multi-organ failure requiring an extensive treatment. Non-traumatic causes of rhabdomyolysis, like poisonings, appear to be much more frequent than traumatic causes. We present the case of a patient who developed exceptionally massive rhabdomyolysis, with CK up to $516455 \mathrm{U} / \mathrm{l}$, after ingestion of a relatively small dose of a novel psychoactive substance known as "Alice in Wonderland". Laboratory quantification was performed using a validated LC-MS/MS method in a whole blood sample.

Key words: 25I-NBOMe, novel psychoactive substances, designer drug, party pill, rhabdomyolysis, multi organ failure

Received: 11 June, 2018; revised: 10 August, 2018; accepted: 10 September, 2018; available on-line: 19 October, 2018

e-mail: waldman.wojciech@gmail.com

Abbreviations: 25I-NBOMe, 2,5-dimethoxy-4-iodo-N-(2-methoxybenzyl)phenethylamine; HS/GC-MS, head-space gas chromatography mass spectrometry; HPLC-FL, fluorescent high performance liquid chromatography; LC-MS/MS, liquid chromatography with tandem mass spectrometry; LOD, limit of detection; LOQ, limit of quantitation; NPS, novel psychoactive substances; $C T$, computed tomography; CVVHD CiCa, continuous venovenous hemodialysis with citrate calcium; iHD, intermittent hemodialysis; $\mathrm{CK}$, creatine kinase; LDH, lactate dehydrogenase; AIAT, alanine aminotransferase; AspAT, aspartate aminotransferase; CRP, $\mathrm{C}$ reactive protein; INR, international normalized ratio; APTT, activated partial thromboplastin time.

\section{INTRODUCTION}

Compound 25I-NBOMe was created in research laboratories as a potent serotonin (5-HT2A) receptor agonist, but because of its high hallucinogenic properties it has been used as an alternative to other drugs such as lysergic acid diethylamide. This has been associated with severe toxicity and fatalities. Prevalence of 25I-NBOMe use and acute toxicity for the years 2010-2015 are given by Wood (Wood et al., 2015).

Rhabdomyolysis is a condition characterized by damage of muscular tissue with resultant release of electrolytes, myoglobin and other enzymatic proteins, such as $\mathrm{CK}$, lactate dehydrogenase $(\mathrm{LDH})$, alanine aminotransferase (AlAT) and aspartate aminotransferase (AspAT), into circulation. This may lead to hypotonia and renal failure due to complex process of fluid escape from circulation to the injured muscles (Huerta-Alardin et al., 2005; Bosch et al., 2009).
Rhabdomyolysis may be of traumatic or non-traumatic origin. The former is associated with crushing, burning, stenosis or occlusion of blood vessels with resultant ischemia, strenuous physical exercise, prolonged seizures or immobilization. The non-traumatic rhabdomyolysis, which appear to be at least 5 times more frequent, may be a consequence of toxic injury caused by medications, illicit drugs, plant toxins, animal poisons, electrolyte and metabolic disorders, infections, neuroleptic malignant syndrome, dermatomyositis and polymyositis. It is usually the result of multiple contributing factors. (Efstratiadis et al., 2007; Keltz et al., 2013).

It is noteworthy that despite the fact that rhabdomyolysis can result from exposure to at least 150 various medications and toxins, it is usually a consequence of toxic injury caused by illicit drugs and alcohol (Melli et al., 2005).

Most patients do not show the classical triad of symptoms associated with rhabdomyolysis, i.e. swelling, muscle pain and discoloration of urine.

The individuals with rhabdomyolysis typically present muscle weakness, pain in isolated muscle groups and/ or poor general condition. Biochemical abnormalities include increased activity of CK, observed as early as 4-6 hours after the exposure to an etiological factor of rhabdomyolysis. According to Sharon (Sharon, 2005), the activity of $\mathrm{CK}$ in patients with massive rhabdomyolysis ranges between $10000 \mathrm{U} / 1$ and more than $100000 \mathrm{U} / \mathrm{l}$.

We report a case of a 20 -year-old male who developed massive rhabdomyolysis with a maximum serum concentration of CK exceeding $500000 \mathrm{U} / 1$ (normal limit: <200 U/l) and multi-organ failure after a recreational use of a party pill known as "Alice in Wonderland".

According to the best of our knowledge only Luckoor (Luckoor et al., 2017) described such an extreme increase in CK activity.

Toxicological studies have detected 25I-NBOMe alone as a substance responsible for the clinical picture and the course of intoxication. Laboratory quantification was performed using a validated LC-MS/MS method in a whole blood sample.

\section{MATERIALS AND METHODS}

\section{Clinical part}

A 20-year-old Caucasian male patient with no significant past medical history was admitted to a hospital after a seizure episode he experienced during a party. According to the witnesses, just before the 
Table 1. The most important abnormalities in physical examination and main treatment strategy

\begin{tabular}{|c|c|c|}
\hline System & Main physical findings & Main treatment strategy \\
\hline Glasgow Coma Score & 4 points on $(E 1+V 1+M 2)$ & Intubation \\
\hline State of consciousness & Deeply unconscious & \\
\hline Neurological condition & $\begin{array}{l}\text { Presented with periodical strains and seizure episo- } \\
\text { des }\end{array}$ & Antiepileptic treatment \\
\hline Cardio-circulatory system & $\begin{array}{l}\text { Supraventricular tachyarrhythmia, } \\
\text { paroxysmal atrial fibrillation, sinus bradycardia, hy- } \\
\text { potension }\end{array}$ & $\begin{array}{l}\text { Metoprolol and amiodarone, } \\
\text { intensive fluid repletion, continuous infusion of } \\
\text { noradrenaline }\end{array}$ \\
\hline Respiratory system & $\begin{array}{l}\text { Tachypnea, } \\
\text { hypoxia, } \\
\text { acute respiratory failure }\end{array}$ & $\begin{array}{l}\text { Mechanical ventilation, } \\
\text { tracheotomy }\end{array}$ \\
\hline Renal function & $\begin{array}{l}\text { Oliguria, } \\
\text { gross hematuria, anuria }\end{array}$ & $\begin{array}{l}\text { CVVHDF CiCa, } \\
\text { iHD }\end{array}$ \\
\hline Temperature & Hyperthermia, up to $40^{\circ}-41^{\circ} \mathrm{C}$ & $\begin{array}{l}\text { Antipyretic, } \\
\text { mechanical cooling }\end{array}$ \\
\hline Muscular system & $\begin{array}{l}\text { Generalized muscle edema, } \\
\text { Interfascial tightness syndrome }\end{array}$ & Supportive treatment. \\
\hline Hematology. & $\begin{array}{l}\text { Coagulation disturbances. } \\
\text { anemia, } \\
\text { thrombocytopenia }\end{array}$ & $\begin{array}{l}23 \text { units Fresh Frozen Plasma, } \\
10 \text { units Frozen Erythrocytes, } \\
3 \text { units Platelet Concentrate, }\end{array}$ \\
\hline Metabolism status & Catabolism & $\begin{array}{l}\text { Parental nutrition with Kabiven Peripheral emulsion } \\
\text { for } 30 \text { days, } \\
\text { enteral nutrition }\end{array}$ \\
\hline Infectious complications & $\begin{array}{l}\text { Infection (carbapenem-resistant Acinetobacter bau- } \\
\text { mannii, Staphylococcus aureus, Escherichia coli and } \\
\text { Pseudomonas aeruginosa) in bronchoalveolar lavage } \\
\text { fluid }\end{array}$ & $\begin{array}{l}\text { Wide-spectrum antibiotic therapy (gentamycin, } \\
\text { colistin) }\end{array}$ \\
\hline
\end{tabular}

Legend: CVVHD CiCa; Multifiltrat, continuous venovenous hemodialysis with citrate calcium; iHD; Fresenius, intermittent hemodialysis procedure

attack, the male took an illegal psychoactive agent of unknown name. No traces of opiates, amphetamine, methamphetamine, cocaine, phencyclidine and tetrahydrocannabinol were found in routine toxicological screen of the urine sample. Due to unclear etiology of the patient's condition, comprehensive differential diagnostics were implemented, including computed tomography (CT) of the head and lumbar puncture. None of these tests revealed any significant abnormalities. The most important abnormalities in physical examination, main treatment strategy and biochemical results were shown in Table 1 and Table 2.

The muscle swelling gradually resolved beginning on the 14th day of the hospital stay, and a pulse could be determined on both radial arteries. The status of the patient stabilized during subsequent days, and then gradually improved. Also, normalization of fluid, electrolyte and metabolic balance was observed, along with the return of a spontaneous lower limb mobility in response to touch and acoustic stimulation. After discontinuing the mechanical ventilation, the rehabilitation was intensified, which resulted in a gradual normalization of the patient's motor function.

\section{Analytical part}

Analysis of biological material

Reagents and materials. 25I-NBOMe and mephedrone- $\mathrm{D}_{3}$, used as an internal standard (IS) were purchased from Cerilliant (Round Rock, Texas, USA). Acetonitrile (MeCN) (HPLC-grade) and formic acid (98-100\%) were bought from Merck (Warsaw, Poland).

Blank blood samples used for validation of the method and preparing controls were obtained from
Table 2. Laboratory work-up showed as below

\begin{tabular}{|c|c|c|c|}
\hline Chosen lab tests & Units & $\begin{array}{l}\text { Normal } \\
\text { range }\end{array}$ & $\begin{array}{l}\text { The largest } \\
\text { deviation }\end{array}$ \\
\hline $\mathrm{pH}$ & - & $7.35-7.45$ & 6.4 \\
\hline $\mathrm{pCO}_{2}$ & $\mathrm{mmHg}$ & $35-48$ & 105 \\
\hline $\begin{array}{l}\text { lactate concentra- } \\
\text { tion }\end{array}$ & $\mathrm{mmol} / \mathrm{l}$ & $0.5-1.6$ & $\begin{array}{l}\text { above the } \\
\text { detection limit } \\
>30\end{array}$ \\
\hline Potassium & $\mathrm{mg} / \mathrm{dl}$ & $3.5-5.1$ & 5.2 \\
\hline Calcium & $\mathrm{mg} / \mathrm{dl}$ & $8.8-10.2$ & 7.72 \\
\hline Phosphorus & $\mathrm{mg} / \mathrm{dl}$ & $2.5-4.5$ & 6.2 \\
\hline CK & $\mathrm{U} / \mathrm{I}$ & $<200$ & 516455 \\
\hline Creatinine & $\mathrm{mg} / \mathrm{dl}$ & $0.7-1.2$ & 2.73 \\
\hline AIAT & $\mathrm{U} / \mathrm{I}$ & $5-37$ & 2899 \\
\hline AspAT & $\mathrm{U} / \mathrm{I}$ & $5-37$ & 6722 \\
\hline $\begin{array}{l}\text { Total /direct bili- } \\
\text { rubin }\end{array}$ & $\mathrm{mg} / \mathrm{dl}$ & $<1.2 /<0.3$ & $7.09 / 4.57$ \\
\hline INR & - & $0.8-1.2$ & 3.67 \\
\hline Prothrombin activity & $\%$ & $80-120$ & 27 \\
\hline APTा & s & $26-37$ & 75 \\
\hline APTT ratio & - & $0.80-1.20$ & 2.25 \\
\hline D-dimer & $\mathrm{ng} / \mathrm{ml}$ & $<500$ & 55342 \\
\hline Fibrynogen & $\mathrm{g} / \mathrm{l}$ & $1.80-3.50$ & 1.58 \\
\hline Antithrombin III & $\%$ & $80-120$ & 29 \\
\hline CRP & $\mathrm{mg} / \mathrm{l}$ & $<5.0$ & 154.7 \\
\hline
\end{tabular}

Legend: INR, international normalized ratio; APTT, activated partial thromboplastin time; CK, creatine kinase; AspAT, aspartate aminotransferase; AlAT, alanine aminotransferase; CRP, C reactive protein 


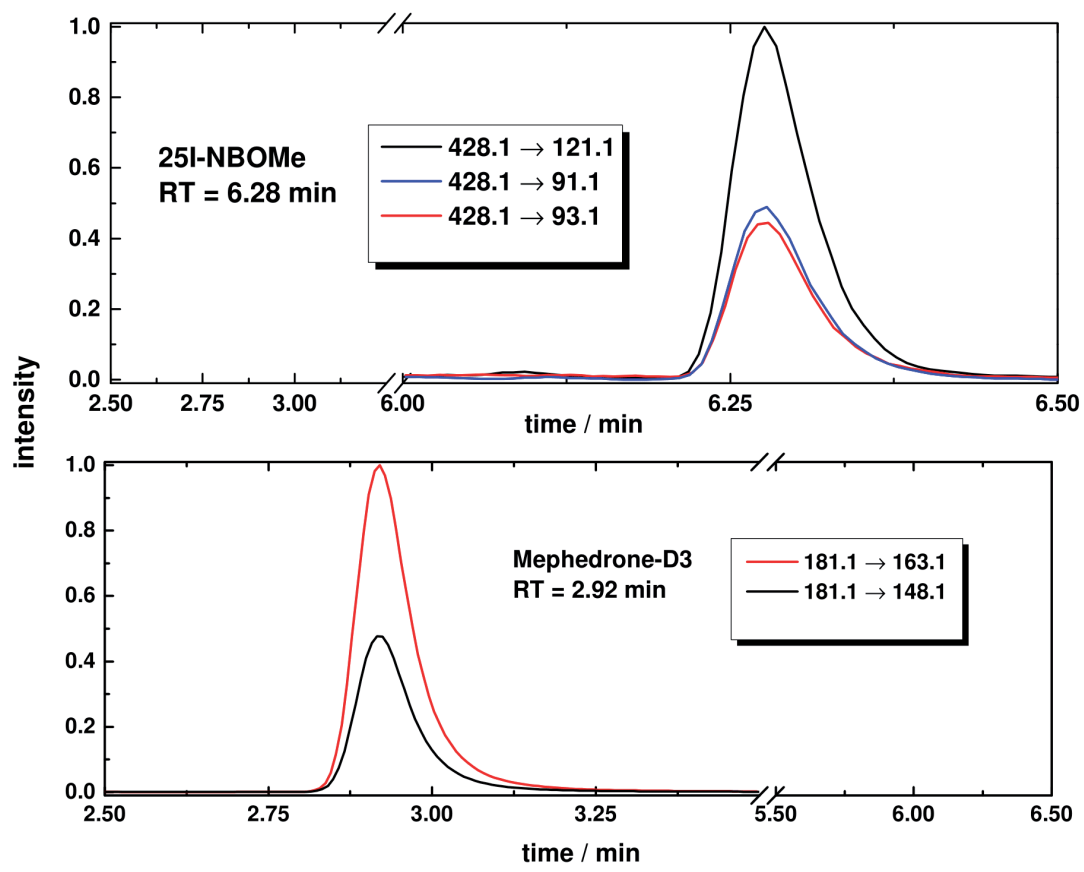

Figure 1. The MRM chromatograms of 25I-NBOMe $(0.24 \mathrm{ng} / \mathrm{ml})$ in the blood sample of the patient, and IS (Mephedrone-D3 at $50 \mathrm{ng} /$ $\mathrm{ml})$, obtained with the targeted method.

a regional blood donation center. The blank blood samples were screened for common drugs of abuse, including 143 NPS (Adamowicz et al., 2015), and results were negative. Biological material was stored at $-20^{\circ} \mathrm{C}$ before the analysis.

Standards, calibrators and controls preparation. Stock solutions of 25I-NBOMe $(1 \mathrm{mg} / \mathrm{ml})$ were stored at $-20^{\circ} \mathrm{C}$. Calibrators were prepared in $0.2 \mathrm{ml}$ of drug-free blood samples by spiking them with 25INBOMe to the concentrations of $0,0.1,0.2,0.4$, and $0.5 \mathrm{ng} / \mathrm{ml}$. Control samples of 25I-NBOMe at 0.1 and $0.5 \mathrm{ng} / \mathrm{ml}$, negative blood controls and mephedrone$\mathrm{D}_{3}$ as IS at the concentration of $50 \mathrm{ng} / \mathrm{ml}$ were also prepared.

Detection, identification and quantification of 25I-NBOMe. 25I-NBOMe was detected and identified in blood of the patient using LC-MS/MS multianalyte method developed by Adamowicz (Adamowicz et al., 2015). This method fulfilled the requirements for screening and qualitative methods as advised by Scientific Working Group for Forensic Toxicology (SWGTOX) (SWGTOX, 2013), where the limit of detection (LOD) for 25I-NBOMe was set at $0.09 \mathrm{ng} /$ $\mathrm{ml}$ in the experiments performed in this article. For quantitative analysis the method was validated as follows. Five microliters of $2 \mu \mathrm{g} / \mathrm{ml}$ methanolic solution of IS were added to the blood samples $(0.2 \mathrm{ml})$ and placed in Eppendorf vials to obtain a final concentration of $50 \mathrm{ng} / \mathrm{ml}$. For all calculations, the ratio of areas of analyte to IS was used. The samples were precipitated with MeCN. To this end, $600 \mu \mathrm{l}$ of $\mathrm{MeCN}$ were added to each sample in $200 \mu \mathrm{l}$ portions, and after each addition, the samples were vortex mixed for $10 \mathrm{~s}$. Next, the samples were mixed for $5 \mathrm{~min}$ and centrifuged at $13000 \mathrm{rpm}$ for $5 \mathrm{~min}$, followed by the transfer of the supernatant into $2 \mathrm{ml}$ glass vials. Next, supernatant was evaporated to dryness under air at $37^{\circ} \mathrm{C}$. The dry residues were dissolved in $100 \mu \mathrm{l}$ of $0.1 \%$ formic acid in water $(\mathrm{v} / \mathrm{v})$ and transferred to in- serts placed in autosampler vials. The compound was quantified using five-point blood calibration curves.

\section{Instrumental analysis}

The blood extracts were analysed using an Agilent Technologies 1200 series liquid chromatograph coupled to a 6460 Triple Quad mass spectrometer. Separation was achieved on a Zorbax SB-C18 $(2.1 \mathrm{~mm} \times 50 \mathrm{~mm}$, $1.8 \mu \mathrm{m})$ column (Perlan Technologies, Warsaw, Poland) maintained at $25^{\circ} \mathrm{C}$. The mobile phase consisting of $0.1 \%$ formic acid in $\mathrm{MeCN}(\mathrm{v} / \mathrm{v})$ and $0.1 \%$ formic acid in water (v/v) was composed under the following gradient conditions (shown in relation to $\mathrm{MeCN}$ content): 0 min $-10 \%, 6 \mathrm{~min}-100 \%, 7 \mathrm{~min}-10 \%$, and $14 \mathrm{~min}-10 \%$. The flow rate was $0.3 \mathrm{ml} / \mathrm{min}$. The injection volume was $10 \mu \mathrm{l}$. Dynamic multiple reaction monitoring (dMRM) with positive ion detection was applied. In targeted assay the precursor and three fragment ions of $25 \mathrm{I}-\mathrm{NBOMe}$ 428.1 $\rightarrow$ 121.0, 428.1 $\rightarrow$ 93.0, 428.1 $\rightarrow$ 91.0, and of mephedrone- $\mathrm{D}_{3}: \mathbf{1 8 1 . 1} \rightarrow$ 163.1, $181.1 \rightarrow$ 148.1, 181.1 $\rightarrow$ 91.1 (the quantifier shown in bold) were selected for monitoring. Retention time of 25I-NBOMe was 6.28 min, relative retention time $-2.92 \mathrm{~min}$, total analysis time - $14 \mathrm{~min}$. The mass detector parameters were as follows: capillary voltage: $3000 \mathrm{~V}$, gas flow $\left(\mathrm{N}_{2}\right)$ : $10 \mathrm{l} /$ min, and gas temperature: $325^{\circ} \mathrm{C}$, sheath gas flow: $10 \mathrm{l} /$ min, sheath gas temperature: $325^{\circ} \mathrm{C}$, nebulizer pressure: 40 psi, cycle time: $500 \mathrm{~ms}$, minimum dwell time: 38.17 $\mathrm{ms}$, maximum dwell time: $246.50 \mathrm{~ms}$, and retention time window: 2 min. The fragmentor voltages and collision energies for 25I-NBOMe were: $118 \mathrm{~V}$ and 20, 36 and $56 \mathrm{~V}$, and for mephedrone- $\mathrm{D}_{3}: 87 \mathrm{~V}$ and 8 and $20 \mathrm{~V}$, respectively.

\section{Toxicological results}

Targeted method validation parameters. Results of validation of LC-MS/MS method for a quantitative assay for 25I-NBOMe analysis in blood were as follows. The direct method was found to be selective for 
25I-NBOMe. No interfering peaks were observed in the extract of analyte-free blood collected from five persons. Interferences with common drugs typically taken in combination by the drug addicts, and other 141 NPS, were tested and could be excluded due to different retention time and MRM transitions. The LOD was estimated as signal to noise, $\mathrm{S} / \mathrm{N}=3$, and it was $0.09 \mathrm{ng} / \mathrm{ml}$ for the transition with the lowest intensity (Adamowicz et al., 2015). The five-point blood calibration curve was prepared (number of replicates for each level, $n=3$ ) in the range of $0.1-0.5 \mathrm{ng} / \mathrm{ml}$. The value of limit of quantitation (LOQ) was assumed to be the lowest point from the calibration curve, and it was $0.1 \mathrm{ng} / \mathrm{ml}$. The assay was linear in the range of LOQ to the highest calibrator, which was $0.5 \mathrm{ng} / \mathrm{ml}$. The matrix effect at the concentration of $0.5 \mathrm{ng} / \mathrm{ml}(\mathrm{n}=3)$ was calculated by comparing the response (analyte area/IS area) measured for 25I-NBOMe and blank blood extract samples. Matrix effect for 25I-NBOMe was $76 \%$ on average, and showed moderate signal suppression.

Carryover effect should be always considered when working with sub-nanogram quantities. Two main actions were taken to monitor it. First, we analyzed a blank blood sample before the case sample, since the injection of solvent is usually ineffective, and second, we compared the quantitative results of two consecutive case samples. The routine handling of the case samples was separated from the calibration samples.

The reconstituted extracts were stable for a period of more than $24 \mathrm{~h}$ at room temperature.

\section{The clinical implications}

The MRM chromatogram of the blood sample of the patient, obtained by the targeted method, is presented in Fig. 1. The concentration of 25I-NBOMe in blood of the patient, determined by direct analysis using validated LC-MS/MS method, was $0.24 \mathrm{ng} / \mathrm{ml}$ on admission to the hospital. Initial toxicological screens and analyses were performed on the blood samples, including volatiles by head-space gas chromatography mass spectrometry (HS/GC-MS), immunoassay for several classes of drugs, and a screen for other $\mathrm{pH}$-dependent (acidic and alkaline) extractable drugs by GC-MS. Additionally, a targeted analysis for LSD, using fluorescent high performance liquid chromatography (HPLC-FL), was also performed. No volatiles, drugs, or LSD were detected.

\section{DISCUSSION}

Recently, numerous cases of severe poisonings and fatal intoxications, especially in teenagers and young adults who have consumed blotter papers containing 25I-NBOMe and/or ingested or smoked other new psychoactive substances (NPS), have been reported all over the world. (Wood et al., 2015).

Use of 25I-NBOMe in both liquid and powder form has been described, with many potential routes of administration, including inhalation of vapor, nasal insufflation, oral ingestion, sublingual/buccal administration, and intravenous injection (Weaver et al., 2015).

The most common clinical presentations were sympathomimetic toxidrome (tachycardia, hypertension, mydriasis, agitation, and hypokalemia) plus hallucinations, bizarre behavior, and persistent seizure activity likely associated with serotonergic toxicity (Rose et al., 2012).

Among others, rhabdomyolysis is a relatively common complication of severe NBOMe toxicity (Halberstadt. 2017). One of rhabdomyolysis markers is high activity of creatine kinase in blood (exceeding the normal upper limit 10-25 times, Linares et al., 2009).

A small active dose of 25I-NBOMe and its analogs leads to low concentrations of the compound in the organism, therefore analytical methods to detect and quantify this substance in bio-samples must be highly accurate, sensitive and specific. The most suitable method for this purpose is high performance liquid chromatography with tandem mass spectrometry (LC-MS/MS) Johnson et al., 2014).

Up to now, limited data have been published concerning concentrations of 25I-NBOMe in intoxicated and fatally poisoned persons, especially after just a single ingestion of this drug. Hill et al. identified, but without quantification, 25I-NBOMe in plasma samples from seven patients (Hill et al., 2013). In the serum specimen drawn from an 18-year-old male admitted to an emergency department, 25I-NBOMe was detected in concentration of $0.76 \mathrm{ng} / \mathrm{ml}$ (Rose \& Poklis et al., 2013). In 2014 Poklis presented first postmortem case of 25I-NBOMe intoxication documented by toxicological analysis of tissues and body fluids (Poklis et al., 2014). Hermanns-Clausen described a case of a rapid degradation of 25I-NBOMe metabolites in serum after mistaken intake of its concentrated solution. At 50 minutes and 13 hours after the drug ingestion, the concentrations of 25I-NBOMe in serum were 34 and $4.2 \mathrm{ng} / \mathrm{ml}$, respectively (Hermanns-Clausen et al., 2017). In the postmortem heart blood taken from a 16 year old male, who was partying with friends and used a drug that was spotted on blotter paper, the toxicological analyses revealed 25I-NBOMe present at concentration of $19.8 \mathrm{ng} / \mathrm{ml}$ (Shanks et al., 2014).

\section{CONCLUSIONS}

Validated LC-MS/MS method is the effective tool to measure the concentration of 25I-NBOMe in blood.

25I-NBOMe appears to be potent with a reported concentration of $0.24 \mathrm{ng} / \mathrm{ml}$ in blood and can result in life-threatening overdose.

The use of new psychoactive substances containing 25I-NBOMe may result in massive rhabdomyolysis associated with multi-organ failure, sepsis, and severe coagulopathies.

Early CVVHD CiCa seems to be efficient in normalizing disorders associated to muscle injury and treating complications of severe rhabdomyolysis.

\section{Declaration of interest}

The authors declare no conflict of interest.

\section{Acknowledgements}

This research received no specific grant from any funding agency in the public, commercial, or not-forprofit sectors

\section{REFERENCES}

Adamowicz P, Tokarczyk B (2015) Simple and rapid screening procedure for 143 new psychoactive substances by liquid chromatography-tandem mass spectrometry. Drug Test Analysis 8: 652-667. https://doi.org/10.1002/dta.1815

Bosch X, Poch E, Grau JM (2009) Rhabdomyolysis and acute kidney injury. N Engl J Med 361: 62-72. https://doi.org/10.1056/NEJMra0801327

Efstratiadis G, Voulgaridou A, Nikiforou D, Kyventidis A, Kourkouni E, Vergoulas G (2007) Rhabdomyolysis updated. Hippokratia 11: 129-137 
Halberstadt AL (2017) Pharmacology and Toxicology of N-Benzylphenethylamine ("NBOMe") Hallucinogens. Curr Top Behav Neurosci 32: 283-311

Hermanns-Clausen M, Angerer V, Kithinji J, Grumann C, Auwärter V (2017) Bad trip due to 25I-NBOMe: a case report from the EU project SPICE II plus. Clin Toxicol (Phila) 55: 922-924. https://doi. org/10.1080/15563650.2017.1319572

Hill SL, Doris T, Gurung S, Katebe S, Lomas A, Dunn M, Blain P, Thomas SH (2013) Severe clinical toxicity associated with analytically confirmed recreational use of 25I-NBOMe: case series. Clin Toxicol 51: 487-492. https://doi.org/10.3109/15563650.2013.802795

Huerta-Alardin AL, Varon J, Marik PE (2005) Bench-to-bedside review: Rhabdomyolysis - an overview for clinicians. Crit Care 9: 158-169. https://doi.org/10.1186/cc2978

Johnson RD, Botch-Jones SR, Flowers T, Lewis CA (2014) An evaluation of 25B-, 25C-, 25D-, 25H-, 25I- and 25T2-NBOMe via LCMS-MS: method validation and analyte stability. J Anal Toxicol 38: 479-484. https//doi.org/10.1093/jat/bku085

Keltz E, Khan FY, Mann G (2013) Rhabdomyolysis. The role of diagnostic and prognostic factors. Muscles Ligaments Tendons J 3: 303-312

Linares LA, Golomb BA, Jaojoco JA, Sikand H, Phillips PS (2009) The modern spectrum of rhabdomyolysis: drug toxicity revealed by creatine kinase screening. Curr Drug Saf 4: 181-187. https://doi. org/10.2174/157488609789007010

Luckoor P, Salehi M, Kunadu A (2017) Exceptionally high creatine Kinase $(\mathrm{CK})$ levels in multicasual and complicated rhabdomyolysis: a case report. Am J Case Rep 18: 746-749. https://doi.org/10.12659/ AJCR.905089

Melli G, Chaudhry V, Cornblath DR (2005) Rhabdomyolysis: an evaluation of 475 hospitalized patients. Medicine 84 : 377-385. https://doi. org/10.1097/01.md.0000188565.48918.41
Poklis JL, Devers KG, Arbefeville EF, Pearson JM, Houston E, Poklis A (2014) Postmortem detection of 25I-NBOMe [2-(4-iodo-2,5dimethoxyphenyl)-N-[(2-methoxyphenyl)methyl]ethanamine $]$ in fluids and tissues determined by high performance liquid chromatography with tandem mass spectrometry from a traumatic death. Forensic Sci Int 234: e14-e20. https://doi.org/10.1016/j.forsciint.2013.10.015

Rose SR, Cumpston KL, Stromberg PE, Wills BK (2012) Severe poisoning following self-reported use of 25-I, a novel substituted amphetamine. Clin Toxicol 50: 707-708

Rose SR, Poklis JL, Poklis A (2013) A case of 25I-NBOMe (25-I) intoxication; a new potent 5HT2a agonist designer drug. Clin Toxicol 51: 174-177. https://doi.org/10.3109/15563650.2013.772191

Scientific Working Group for Forensic Toxicology (SWGTOX) (2013) Standard practices for method validation in forensic toxicology. J Anal Toxicol 37: 452-474. https://doi.org/10.1093/jat/bkt054

Shanks KG, Sozio T, Behonick GB (2015) Fatal intoxications with 25B-NBOMe and 25I-NBOMe in Indiana during 2014. J Anal Toxicol 39: 602-606. https//doi.org/10.1093/jat/bkv058

Sharon GC (2005) Rhabdomyolysis. Orthop Nurs 24: 443-447

Weaver MF, Hopper JA, Gunderson E W (2015) Designer drugs 2015: assessment and management. Addict Sci Clin Pract 10: 8. https://doi. org/10.1186/s13722-015-0024-7

Wood DM, Sedefov R, Cunningham A, Dargan PI (2015) Prevalence of use and acute toxicity associated with the use of NBOMe drugs. Clin Toxicol (Phila) 53: 85-92. https://doi:10.3109/15563650.2015.1 004179 